\title{
APPLICATION OF HYALURONIC ACID SODIUM SALT AND VITAMIN C IN THE THERAPY OF DOGS WITH HYPERTROPHIC OSTEODYSTROPHY
}

\author{
ROMAN ALEKSIEWICZ, KRZYSZTOF LUTNICKI ${ }^{1}$, RENATA KOMSTA ${ }^{2}$, \\ KRZYSZTOF KOSTRO ${ }^{3}$, AND JACEK SZULC \\ Polish Association of Small Animal Veterinarians, 20-612 Lublin, Poland \\ ${ }^{1}$ Clinic of Internal Medicine, Department of Internal Diseases of Farm Animals and Horses, \\ ${ }^{2}$ Radiology and Ultrasound Laboratory, Department of Surgery, \\ ${ }^{3}$ Department of Epizootiology and Clinic of Infectious Diseases, \\ Faculty of Veterinary Medicine University of Life Sciences in Lublin, 20-612 Lublin, Poland \\ krzysztof.lutnicki@up.lublin.pl
}

Received: August 31, 2012

Accepted: May 4, 2013

\begin{abstract}
Radiographic examination of the distal radius and ulna of dogs showed changes in metaphyseal areas of both bones characteristic of hypertrophic osteodystrophy (HOD). The serum of the patients showed increased activity of alkaline phosphatase (ALKP) and elevated concentrations of $\mathrm{Ca}$ and $\mathrm{P}$. Oral application of vitamin $\mathrm{C}$ and injection of sodium salt of hyaluronic acid in the bolus caused a reduction in swelling, disappearance of pain symptoms around the joints, and increased appetite. Radiographic examinations performed on the $60^{\text {th }} \mathrm{d}$ of treatment revealed the withdrawal of the changes characteristic for HOD. The chosen biochemical parameters tested during the treatment showed a decrease in comparison to the values before treatment, namely: ALKP by $27.7 \%$, Ca by $22.2 \%$, P by $12.3 \%$, and $\mathrm{Mg}$ by $2.4 \%$. Clinical condition of the animals was defined as good or very good. The use of hyaluronic acid and vitamin $\mathrm{C}$ in the treatment of HOD in the first stage of the disease proved to be highly successful, resulting in the inhibition of the disease course.
\end{abstract}

Key words: dog, hypertrophic osteodystrophy, hyaluronic acid, vitamin C, therapy.

Hypertrophic osteodystrophy (HOD) is a disease of dogs at developmental age. It affects mainly medium, large, and giant breeds, such as the German Dog, Alaskan malamute, Irish setter, Doberman, and Pinscher. The disease usually starts between the third and fifth month of age. Clinical trials revealed that at the initial stage of the disease, the metaphyseal regions show swelling, tenderness, and growth of local temperature. The symptoms are usually accompanied by fever, aversion to food, and fast weight loss (23). During the initial period of HOD, radiography reveals bilateral radiolucent areas in the metaphyses $(15,22,30)$. Additionally, an increased activity of alkaline phosphatase (ALKP) and elevated concentrations of $\mathrm{Ca}$ and $\mathrm{P}$ are observed in serum $(3,11,12,19,23,32)$. An excessive supplementation with calcium preparations, excessive high-calorie diets used during dogs' growth, stress, skin reactions after vaccination against rabies and distemper are considered to be the main aetiological factors of the disease (22). Deficiency in vitamin $\mathrm{C}$ is also considered as a probable cause of HOD (8). This theory has gained attention and is under a further investigation. Some authors point out the effect of ascorbic acid and glycosaminoglycans (GAG-s) on the biosynthesis and maturation of collagen and the participation of free radicals in the pathogenesis of HOD $(2,5)$.

Exogenous hyaluronic acid (HA) has a direct effect on chondrocytes through CD44 cell-surface glycoprotein, stimulating them to synthesise collagen (5); it also stimulates the cells to synthesise endogenous $\mathrm{HA}$, and this process is dependent on the presence of ascorbic acid. Exogenous macromolecular HA molecules (high molecular weight hyaluronan-HMWH) exhibit cytoprotective effects in fibroblasts, chondrocytes, and other cells $(4,31)$. Hyaluronic acid enhances the mechanical functions of collagen, is necessary for binding collagen fibers into bundles. It is also responsible for the repair and replacement of damaged and dead collagen fibers (5).

The aim of the study was to determine the effect of administration of the sodium salt of hyaluronic acid and vitamin $\mathrm{C}$ to dogs with diagnosed hypertrophic osteodystrophy in the early stages of the disease. 


\section{Material and Methods}

Animals. During 2009-2011, treatment for HOD was applied to 15 dogs of various breeds, sex, not sterilised, aged between 4 and 6 months, with the weight of 15 to $25 \mathrm{~kg}$. Before the administration of the treatment and during the experiment, the dogs were fed a complete feed for growing animals which did not contain additional supplements. Dogs used in the study demonstrated: lameness, reluctance to walk, and swelling of soft tissue in the metaphyseal regions. In all dogs, foreleg lameness, tenderness around the wrists, and local hyperthermia were found. The animals moved reluctantly, and had a temporary increase in body temperature and anorexia. Their body weight was in all cases reduced by $8 \%-10 \%$ compared to the normal body weight assigned to a particular dogs' breed or age. The observed pathological changes were bilateral and concerned the distal metaphyses of the radius and ulna.

Design of the experiment. The dogs were given intravenously 5 times at $10 \mathrm{~d}$ intervals - $20 \mathrm{mg}$ of sodium salt of hyaluronic acid with a molecular weight of $5-7 \times 10^{5}$ Da (Hyonate, Bayer Healthcare AG, Germany) as a bolus, and orally $40 \mathrm{mg} / \mathrm{kg} / \mathrm{d}$ of ascorbic acid (Polfa, Poland). The dogs did not receive any other medicines during the treatment.

Blood chemistry tests were performed in all dogs with the use of a Vettest biochemical analyser (IDEXX) in order to determine alkaline phosphatase (ALKP) activity and concentrations of $\mathrm{Ca}, \mathrm{Mg}$, and $\mathrm{P}$ ions. Examinations were done on the day $\mathrm{O}$ (before the treatment), on day 20, 40 and 60 (at the end of treatment). On the $60^{\text {th }} \mathrm{d}$ of the treatment, an X-ray examination was performed.

Statistical analysis. The results of blood chemistry, presented as mean values with standard deviation (SD), were subjected to statistical analysis and related to the reference values. The significance of differences was examined using Student's $t$-test for unconnected variables. The analysis of correlation was made determining the Parson ( $\mathrm{r}$ ) coefficients, and the intensity of dependence of two variables was interpreted according to the scale of Stanisz (27).

\section{Results}

The radiographs before treatment showed changes characteristic of hypertrophic osteodystrophy: an uneven radiolucent area in the metaphyses and lesions, which resembled the subperiosteal lytic defects and were located within metaphyses, reaching different depths. The changes are marked as "A" on Fig. 1. Patients revealed the changes in their bone structure of metaphyseal areas of both bones. Radiographic image of the radial bone displayed an uneven radiolucent zone in the metaphysis that was paralleled to the physis. That radiolucent zone resembled the radiographic image of the growth plate.

The changes in the ulna were similar; however, in individual cases were limited to subperiosteal cavities in the metaphyseal region. The changes in both thoracic limbs were symmetric. Based on clinical and radiological examination, an early stage of HOD was diagnosed in all cases.

The changes in the concentrations of $\mathrm{Ca}, \mathrm{P}$, and $\mathrm{Mg}$ and activity of ALKP are presented on Figs 2-5. Mean values of biochemical parameters determined before treatment were as follows: ALKP - 322.4 U L, $\mathrm{Mg}-1.66 \mathrm{mg} / \mathrm{dL}, \mathrm{P}-10.93 \mathrm{mg} / \mathrm{dL}$, and $\mathrm{Ca}-14.62$ $\mathrm{mg} / \mathrm{dL}$. Mean values of the parameters determined on the $60^{\text {th }} \mathrm{d}$ of the treatment were: ALKP $-233.2 \mathrm{U} / \mathrm{L}, \mathrm{Mg}$ - $1.62 \mathrm{mg} / \mathrm{dL}, \mathrm{P}-9.59 \mathrm{mg} / \mathrm{dL}$, and Ca - $11.37 \mathrm{mg} / \mathrm{dL}$.

In all cases, the oral administration of vitamin $\mathrm{C}$ and HA sodium salt injections in the first week of treatment resulted in reduction of swelling, disappearance of symptoms of pain around the joints, and increased appetite. Physical activity of treated dogs gradually improved after $14 \mathrm{~d}$, and between 20 and $30 \mathrm{~d}$ of treatment was assessed by the owners as good and very good. Radiographs made on the $60^{\text {th }} \mathrm{d}$ revealed in all cases the regression of changes characteristic for HOD, i.e. loss of bone defects, normal tissue contouring, and proper radiodensity of the radius and ulna. The radiodense areas in the examined metaphyseal regions are marked as "B" in Fig. 6.

All investigated parameters indicated a marked decrease during treatment. This decline on the $60^{\text {th }}$ day was for ALKP - 27.7\%, Ca - 22.2\%, P - 12.3\%, and Mg - $2.4 \%$ of the values indicated prior to treatment. For ALKP, the average decline in its activity was $9.23 \%$ among the successive tests. The average decrease in concentration of $\mathrm{Ca}, \mathrm{P}$, and $\mathrm{Mg}$ among successive measurements reached $7.4 \%, 8.2 \%$, and $0.8 \%$, respectively. $\mathrm{Mg}$ concentration decreased rapidly between 0 and $20^{\text {th }} \mathrm{d}$ after the first administration of HA and then between $20^{\text {th }}$ and $60^{\text {th }} \mathrm{d}$ it rose by $22.3 \%$. Pearson correlation coefficient (r) for each link is shown in Fig. 7 and Fig. 8.

\section{Discussion}

Polyaetiological nature of HOD is still unclear and hereditary predispositions to the disease have not been documented. The intensity of symptoms may vary in terms of quantity and quality also among dogs coming from the same litter (8). The cortical defects in the metaphysical area, observed in the clinical X-ray images before starting treatment, were characteristic for HOD and were similar to those described by Koper and Olsson $(15,22)$. Their formation is associated with excessive deposition of the osteoid, which pushes the periosteum to the edge and its mineralisation is delayed $(18,30)$. Radiolucent zones visualised on radiographs were identified as foci of bone desorption. Similar pathological changes characteristic of HOD were also described by other authors $(15,18,20,30)$.

The clinical symptoms in 15 dogs treated in the study, were consistent with HOD as described in literature $(8,15,24)$. 


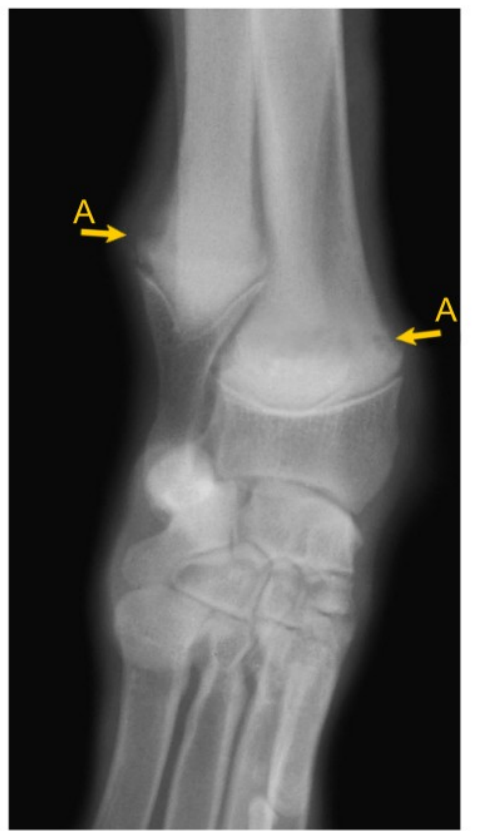

Fig. 1. „A" - radiolucent areas in the metaphyses of the distal radius and ulna. The changes associated with the radius are more prominent. Four-month-old male German shepherd. Status before treatment

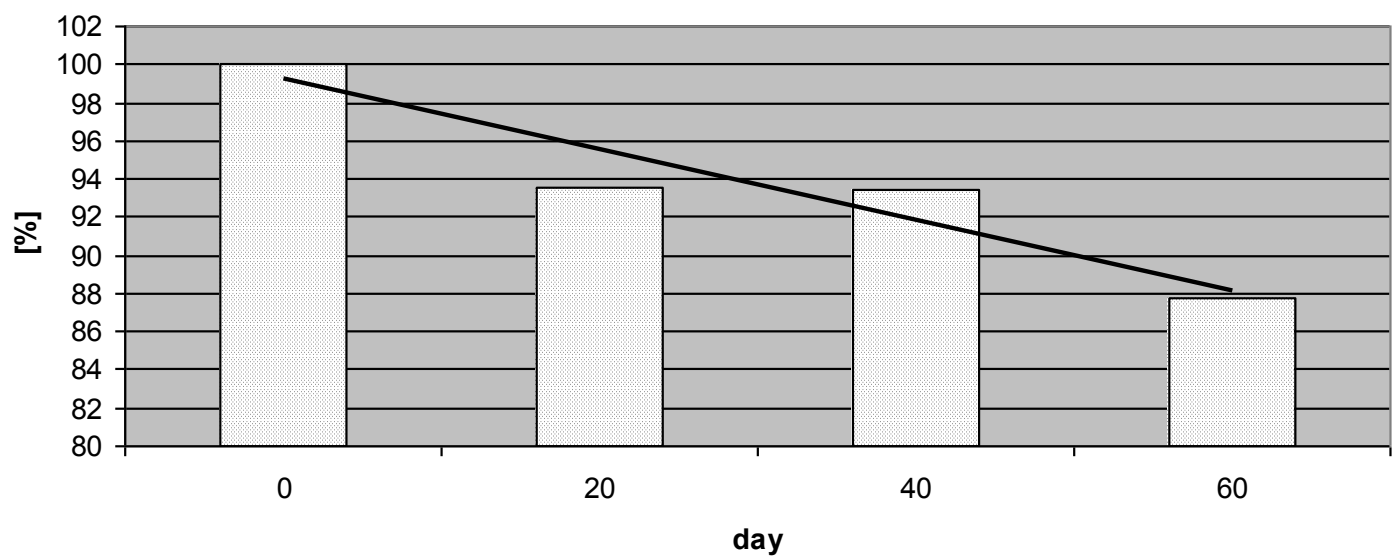

Fig. 2. Concentration of $\mathrm{P}$ in serum during treatment

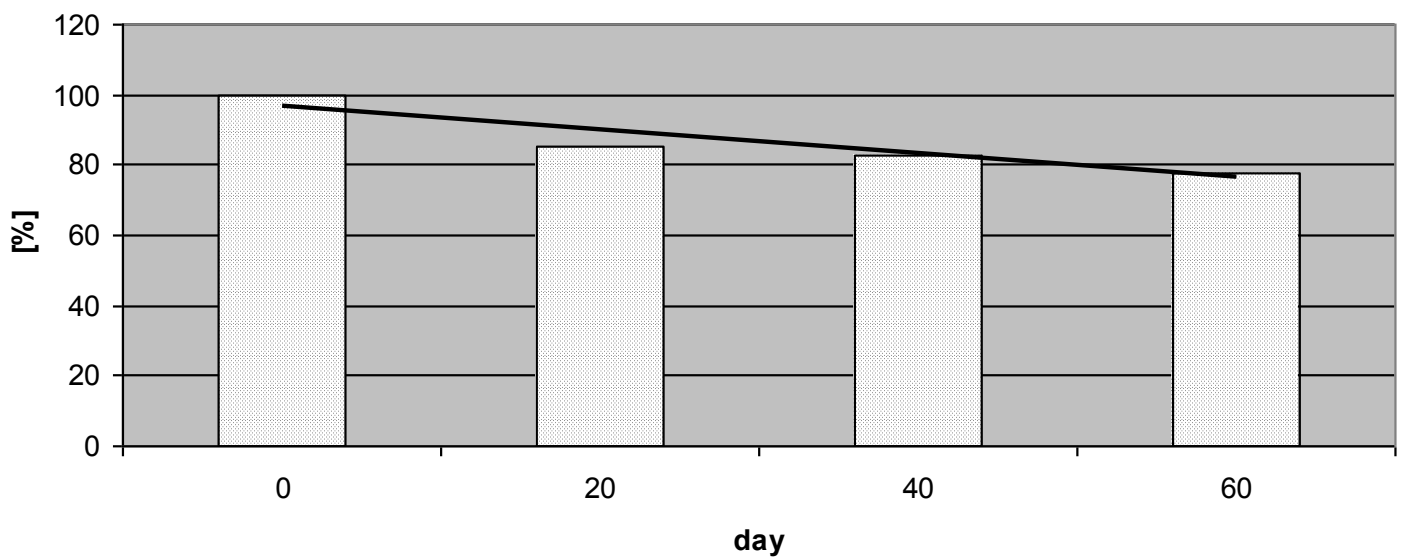

Fig. 3. Concentration of $\mathrm{Ca}$ in serum during treatment 


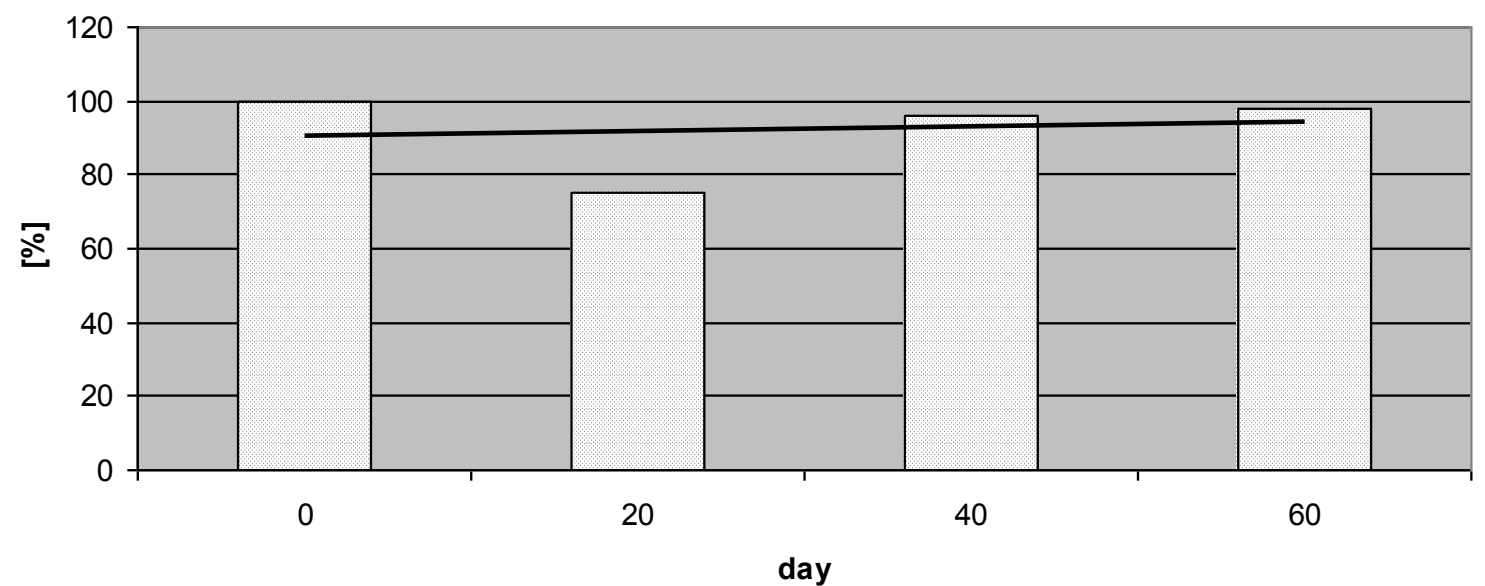

Fig. 4. Concentration of $\mathrm{Mg}$ in serum during treatment

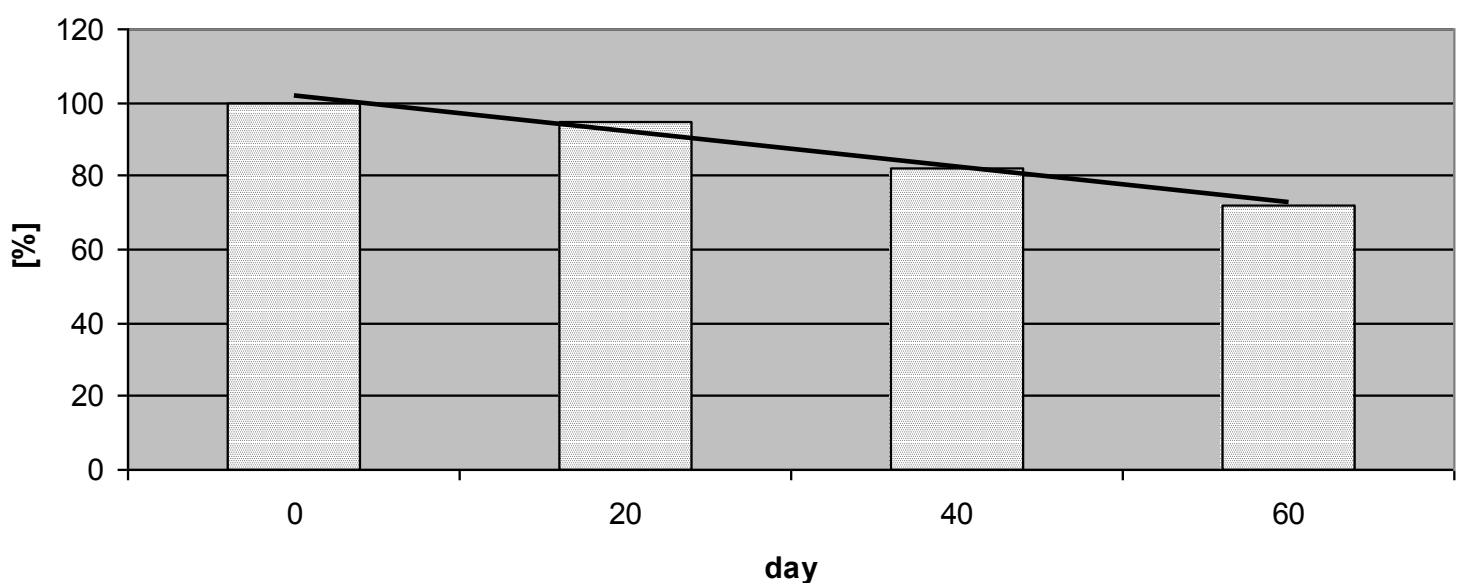

Fig. 5. Activity of alkaline phosphatase during treatment

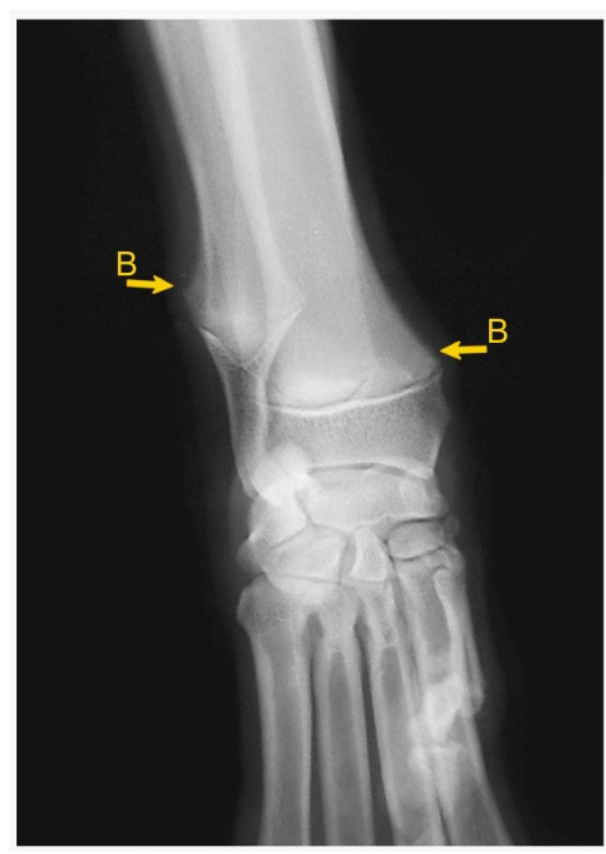

Fig. 6. "B" - the increased metaphyseal sclerosis, which reflects the accumulation of Ca in the process of reparations. Six-month-old male German shepherd. The $60^{\text {th }} \mathrm{d}$ of treatment 


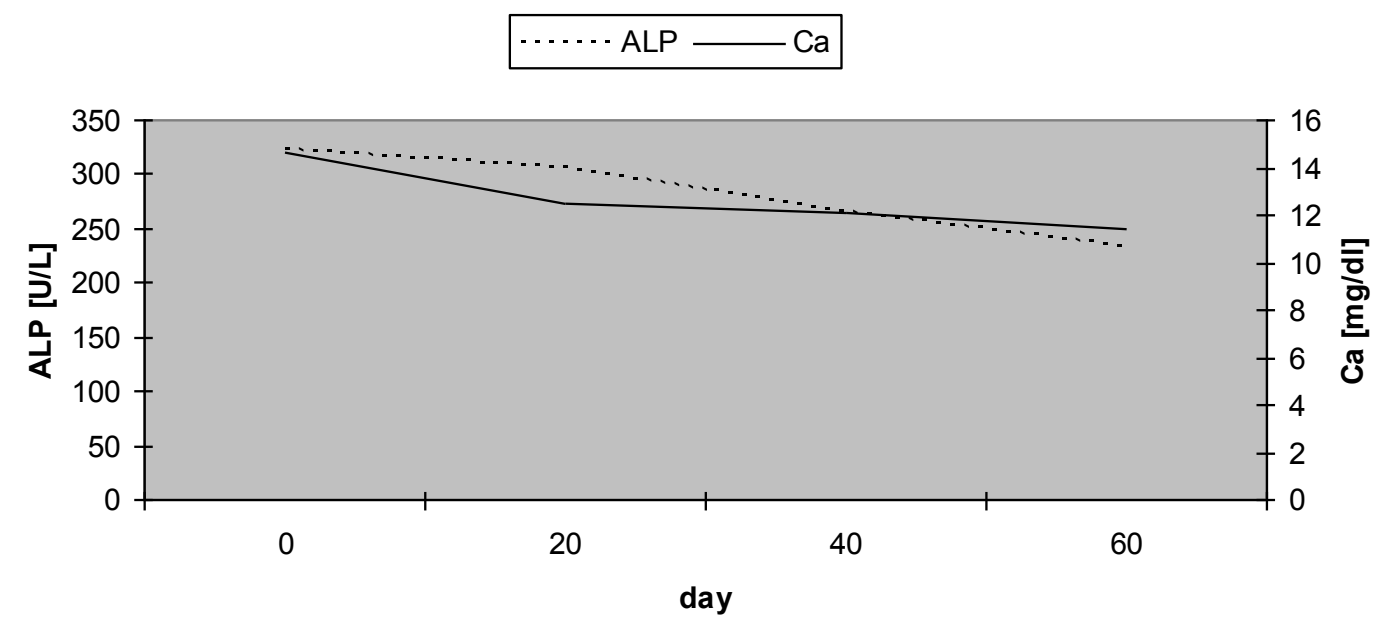

Fig. 7. Dependences and correlation coefficients of alkaline phosphatase activity (ALP) and $\mathrm{Ca}$ concentration during treatment; correlation coefficient $\mathrm{r}=0.876580441$

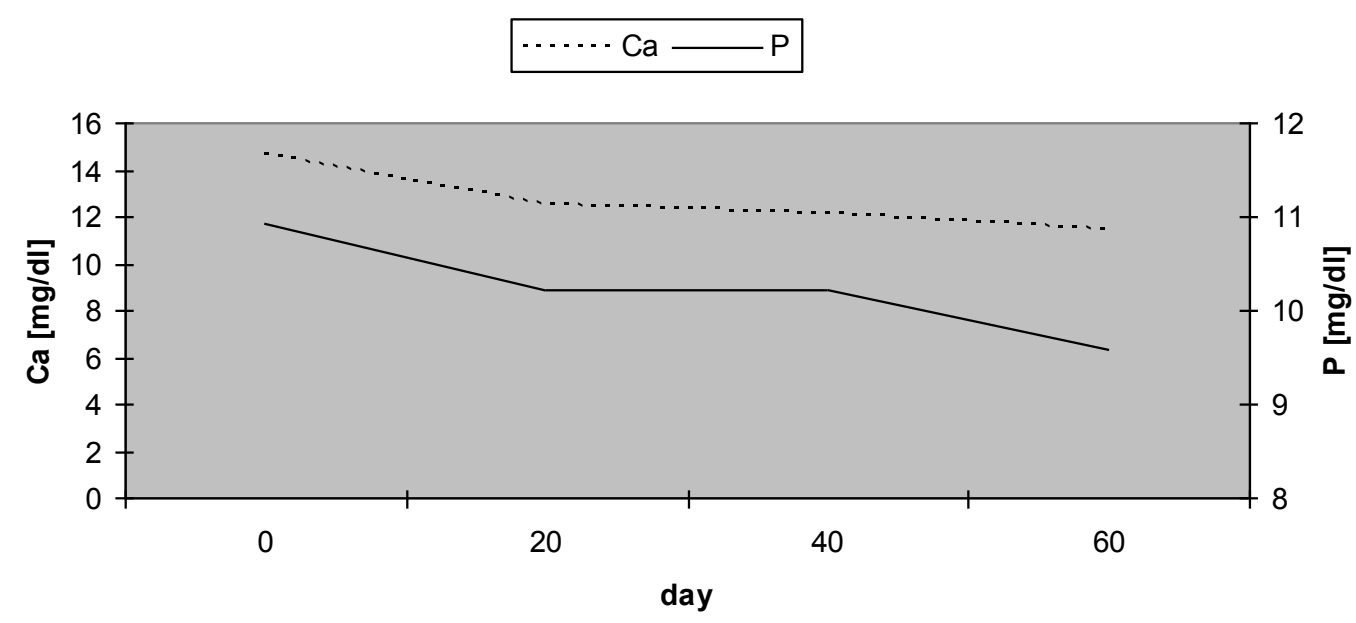

Fig. 8. Dependences and correlation coefficients of $\mathrm{Ca}$ and $\mathrm{P}$ concentrations during treatment; correlation coefficient $\mathrm{r}=0.963374011$

Examinations made on the $60^{\text {th }} \mathrm{d}$ of treatment revealed the disappearance of radiological features characteristic of HOD. A return of normal contour and radiodensity of the radius and ulna in the examined area has occurred. The increased metaphyseal sclerosis, resulting from the recovery and reflecting the stimulation of osteoblasts in the process of reparations, was also demonstrated. A similar bone remodelling and the seizure of trabecular structure in the phase of recovery in the course of HOD are described by other authors $(12,15,22)$. Osteoblasts produce and secrete into the pericellular space the type I collagen and proteoglycans building intercellular matrix (osteoid), protein precursors and proteins that regulate the bone mineralisation process - osteonectin and osteocalcin. Osteonectin when binding to type I collagen forms a complex in which calcium salts and hydroxyapatite crystals are deposited. Osteocalcin binds calcium ions providing a substrate for bone mineralisation. Mineralisation of osteoid is made by hydroxyapatite crystals linearly arranged along collagen fibbers and growing between them. On the surface of hydroxyapatite crystals, $\mathrm{HPO}_{4}^{-}, \mathrm{HCO}_{3}^{-}, \mathrm{Mg}^{++}, \mathrm{Na}^{+}, \mathrm{F}^{-}$, ions and citrates are adsorbed, which creates the cross linking of $\mathrm{Ca}^{2+}$ ions $(9,24)$. Collagen type I makes up $95 \%$ of the matrix and is the framework of subsequent mineralisation. The correctness of the process of mineralisation is determined by the amount of collagen fibers and their correct structure. The structure of collagen determines the majority of processes in the bone tissue such as bone formation, mineralisation, and obtaining the correct mechanical properties (16). The biosynthesis of collagen is a complex process involving, among others, hydroxylation of proline residues catalysed by prolyl 4-hydroxylase (EC 1.14.11.12) and prolyl 3-hydroxylase (EC 1.14.11.7), and hydroxylation 
of lysine residues catalysed by lysyl hydroxylase (EC 1.14.11.4 ) (2). The activity of the enzymes depends on the presence of ascorbic acid, which prevents the passage of the active $\mathrm{Fe}^{2+}$ ions into inactive, oxidised $\mathrm{Fe}^{3+}$ form (16). In the presence of vitamin $\mathrm{C}$ correct and strong bonds are produced, which play a crucial role in the building of collagen triple helix. Stabilisation of collagen structures (collagen maturation), and giving them the characteristics of the insolubility and resistance to protease activity is the result of the production of cross-links. Goodman et al. (10) and Teare et al. (29) emphasise the role of ascorbic acid in the pathogenesis of HOD.

Olsson (20) has observed that in the course of HOD, the subchondral zone of bone metaphysis has an obliterated trabecular structure and its tissue material does not contain much collagen. Afterwards, he has noted that in this zone, extravasations and blood clots are observed, resulting from microfractures of bone trabeculas due to excessive sensitivity to overload. In the intercellular substance, the hyaluronic acid fills the space between collagen fibers, binds water molecules, improves its cushioning properties, and supplies nutrients $(33,34)$. Its heparinic properties cause the release of blood clots, restitution of flow in the zone of subchondral bone, and elimination of ischaemic foci. Native HA macromolecular molecules are an important anti-inflammatory factor interacting with leukocytes and inhibiting the activity of lysosomal enzymes $(1,5-7,25)$. Hyaluronic acid in the form of heavy chains (HMWH) during the scavenging of ROS has the ability to chelate metal ions $(17,26)$. Taking into account the literature data and the observations, it can be stated that the clinical improvement during the first period of treatment (up to $20 \mathrm{~d}$ ) resulted from the anti-inflammatory and anticoagulant activity of hyaluronic acid and its anticoagulant action led to reperfusion in disease outbreaks. Proper vascularisation and flow maintenance is crucial for proper progress of ossification process $(9$, 24). Vitamin $C$, acting on the sealing up of vascular endothelium, inhibits the development of oedema, which restores the flow around metaphyses. Vitamin C and HA are the "scavengers" of reactive oxygen species (ROS). Their action on the termination of free radical reactions limits the local cytodestruction, which contributes to the extinction of inflammation and consequently reduces pain (14), as reported by dog owners in the first stage of treatment.

Magnesium concentration determines osteoblast activity affecting the level of collagen synthesis and bone mineralisation. Magnesium has a regulatory effect on the mineralisation process promoting the accumulation of $\mathrm{Ca}^{2+}$ ions and inhibiting their excessive accumulation (32). The study demonstrated a very high negative correlation between the concentrations of these ions, while the concentration of magnesium during the treatment was within normal limits. Elevated levels of serum $\mathrm{Ca}^{2+}$ in dogs' serum was the result of the disease and leaching calcium ions from HOD foci. A decrease in the concentration of $\mathrm{Ca}^{2+}$ in the course of treatment and characteristic change of X-ray images indicate the accumulation of calcium and magnesium and confirm the regulatory function of magnesium in the mineralisation. During the tests performed, similar trends in changes of ALKP activity and levels of calcium testify a strong dependence of these parameters. Significant changes in ALKP activity in the course of HOD and correlation with elevated concentrations of $\mathrm{Ca}$ were also described by Ozer et al. (23) and Joiner et al. (12). In the study, it was shown that the changes in serum $\mathrm{P}$ concentrations highly correlated with the change of ALKP activity. The use of hyaluronic acid and vitamin $\mathrm{C}$ in the treatment of HOD in the first stage of the disease has been highly successful, resulting in inhibition of the disease. The recovery from HOD strongly depends on restoration of the correct ossification, which is connected with proper synthesis and metabolism of type I collagen, depending, among other things, on HA and vitamin C $(2,9,10,16$, $24,28,33,34)$.

\section{References}

1. Aleksiewicz R.: Treatment of arthritis of various etiologies with the advancement of the use of glycosaminoglycans. Życie Wet 1988, 8, 233-236.

2. Bennett D.: Nutrition and bone disease in the dog and cat. Vet Rec 1976, 98, 313-321.

3. Boyan B.D., Schwartz Z., Swain L.D.: Matrix vesicles as a marker of endochondral ossification. Connect Tissue Res 1990, 24, 67-75.

4. Campo G.M., Avenoso A., Campo S., D'Ascola A., Ferlazzo A.M., Calatroni A.: Reduction of DNA fragmentation and hydroxyl radical production by hyaluronic acid and chondroitin-4-sulphate in iron plus ascorbate-induced oxidative stress in fibroblast cultures. Free Radic Res 2004, 38, 601-611.

5. Chow G., Knudson G.B., Homandberg G., Knudson W.: Increased expression of CD44 in bovine articular chondrocytes by catabolic cellular mediators. J Biol Chem 1995, 270, 27734-27741.

6. Day A.J., De la Motte C.A.: Hyaluronan cross-linking: a protective mechanism in inflammation? Trends Immunol 2005, 26, 637-643.

7. Evanko S.P., Tammi M.I., Tammi R.H., Wight T.N.: Hyaluronan-dependent pericellular matrix. Adv Drug Deliv Rev 2007, 59, 1351-1365.

8. Franklin M.A., Rochat M.C., Broaddus K.D.: Hypertrophic osteodystrophy of the proximal humerus in two dogs. J Am Anim Hosp Assoc 2008, 44, 342-346.

9. Giusti A., Hamdy N.A., Papapoulos S.E.: Atypical fractures of the femur and bisphosphonate therapy: A systematic review of case/case series studies. Bone 2010, 47, 169-180.

10. Goodman S.A., Montgomery R.D., Fitch R.B., Hathcock J.T., Lauten S.D., Cox N.R., Kincaid S.A., Rumph P.F., Brawnwer W.R., Baker H.J., Lepine A.L., Reinhart G.A.: Serial orthopedic examinations of growing Great Dane puppies fed three diets varying in calcium and phosphorus. In: IAMS Nutrition Symposium Proceedings. Orange Frazer Press-Ohio, 1988, pp. 3-12.

11. Harrus S., Waner T., Aizenberg J., Safra N., Mosenco A., Radoshitsky M., Bark H.: Development of Hypertrophic osteodystrophy and antibody response in a litter of vaccinated Weimaraner puppies. J Small Anim Pract 2002, 43, 27-31. 
12. Joiner K.S., Montgomery R.D.: Pathology in practice. Hypertrophic osteodystrophy. J Am Vet Med Assoc 2011, 238, 1413-1415.

13. Julovi S.M., Yasuda T., Shimizu M., Hiramitsu T., Nakamura T.: Inhibition of interleukin-1 $\beta$-stimulated production of matrix metalloproteinases by hyaluronan via CD44 in human articular cartilage. Arthritis Rheum 2004, 50, 516-525.

14. Kleczkowski M., Kluciński W., Sikora J.: Role of selected minerals in the oxidative processes of the body. Med Weter 2004, 60, 242-245.

15. Koper S., Komsta R.: Hypertrophic osteodystrophy (HOD) in dogs - a retrospective study. Mag Wet 2000, 45, 6-11.

16. Kucharz E.J.: The collagens: biochemistry and pathophysiology. Berlin-New York, Springer Verlag. 1992.

17. Laurent T.C., Fraser J.R.: Hyaluronan. FASEB J 1992, 6, 2397-2404.

18. Morgan J.P.: Radiology of Veterinary Orthopedics Features of Diagnosis. Venture Press, Napa, California, 1999.

19. Nakatani S., Mano H., Ryanghyok I.M., Shimizu J., Wada M.: Excess magnesium inhibits excess calciuminduced matrix-mineralization and production of matrix gla protein (MGP) by ATDC5 cells. Biochem Biophys Res Commun 2006, 348, 1157-1162.

20. Olsson S.E.: General and local etiologic factors in canine osteochondrosis. Vet Quart 1987, 3, 255-257.

21. Olsson S.E.: Osteochondrosis a growing problem to dog breeders. Gaines Dog Res Center 1976, 1, 4- 11.

22. Olsson S.E.: Radiology in veterinary pathology. Acta Radiol Suppl 1972, 319, 255-270.

23. Ozer K., Altunatmaz K., Gülcubuk A.: Hypertrophic osteodystrophy in the dog: 18 cases. Turk J Vet Anim Sci 2004, 28, 761-768.

24. Robey P.G., Boskey A.L.: The biochemistry of bone. In: Osteoporosis. Academic Press, New York, 1995, pp. 95 183.
25. Slevin M., Kumar G., Gaffney J.: Angiogenic oligosaccharides of hyaluronan induce multiple signaling pathways affecting vascular endothelial cell mitogenic and wound healing responses. J Biol Chem 2002, 277, 41046-41059.

26. Šoltés L., Mendichi R., Kogan G., Schiller J., Stankovská M., Arnhold J.: Degradative action of reactive oxygen species on hyaluronan. Biomacromolecules 2006, 7, 659668.

27. Stanisz A.: Przystępny kurs statystyki w oparciu o program Statistica PL. StatSoft Polska, Kraków, 1998, p. 362.

28. Si-Kwang L.: Metabolic disease in animals. Semin Musculoskelet Radiol 2002, 6, 341-346.

29. Teare J.A., Krook L., Kallfelz F.A., Hintz H.F.: Ascorbic acid deficiency and hypertrophic osteodystrophy in the dog: a rebuttal. Cornell Vet 1976, 69, 384-401.

30. Trostel C.T., Pool R.R., McLaughlin R.M.: Canine lameness caused by development of orthopedic diseases: panosteitis, Legg-Calve-Perthes Disease, and hypertrophic osteodystrophy. Compend Cont Educ Pract Vet 2003, 25, 282-292.

31. Wang C.T., Lin Y.T., Chiang B.L., Lin Y.H., Hou S.M.: High molecular weight hyaluronic acid down-regulates the gene expression of osteoarthritis-associated cytokines and enzymes in fibroblast-like synoviocytes from patients with early osteoarthritis. Osteoarthr Cartil 2006, 14, 1237-1247.

32. Wentzell M.L.: Hypertrophic osteodystrophy preceding canine juvenile cellulitis in an Australian shepherd puppy. Can Vet J 2011, 52, 431-434.

33. Vuorio E., de Crombrugghe B.: The family of collagen genes. Ann Rev Biochem 1990, 59, 837-872.

34. Zou L., Zou X., Chen L., Li H., Mygind T., Kassem M., Bünger C.: Effect of hyaluronan on osteogenic differentiation of porcine bone marrow stromal cells in vitro. J Orthop Res 2008, 26, 713-720. 